\title{
Inseguridad jurídica ante el impedimento del ejercicio de la acción pública de inconstitucionalidad dentro del proceso especial para la paz ${ }^{*}$
}

\author{
INSEGURANÇA JURÍDICA PERANTE O IMPEDIMENTO \\ DO EXERCÍCIO DA AÇÃO PÚBLICA DE INCONSTITUCIONALIDADE \\ DENTRO DO PROCESSO ESPECIAL PARA A PAZ
}

\author{
Diana Marcela Joya Rojas"
}

Angye Nathalia Sánchez Muñoz

Recibido: 8 de agosto de 2017 - Aprobado: 4 de octubre de 2017

\section{Resumen}

El presente trabajo investigativo pretende identificar en qué medida los actos legislativos que son expedidos bajo el procedimiento especial para la paz, generan seguridad jurídica, en aras de que su control de constitucionalidad solo se realiza por vicios de procedimiento en su formación y de oficio, sin permitir que se pueda incoar por parte del ciudadano la acción pública de constitucionalidad; razón por la cual se hace necesario establecer la naturaleza jurídica de dichos actos legislativos y determinar el proceso de constitucionalidad, de conformidad con lo establecido por la Corte Constitucional, así mismo, se evidencia que este desbalance jurídico

\footnotetext{
" Artículo producto del proyecto de investigación: "Inseguridad jurídica ante el impedimento del ejercicio de la acción pública de inconstitucionalidad dentro del proceso especial para la paz", gestionado en el programa de la especialización de Derecho Administrativo de la Universidad Libre, Bogotá, Colombia.

* Abogada, Universidad Cooperativa de Colombia, estudiante investigadora. Especialista en Derecho Administrativo. Correo electrónico: diana.joya.r@hotmail.com

*** Abogada, Universidad Militar Nueva Granada, Bogotá, Colombia. Correo electrónico: nathalia. sanchez.003.@gmail.com
} 
tiene solución a través de la emisión de diferentes tipologías de sentencias que puede realizar la Corte Constitucional, con el fin de ejercer un control material y formal sobre dichos actos reformatorios, siendo en el caso concreto la expedición de una sentencia que interprete y adicione la implementación del acuerdo de paz, con el propósito de garantizar el poder constituyente primario, y la democracia participativa como característica fundamental de un Estado social, constitucional y democrático de derecho.

Palabras clave: control constitucional, acto legislativo, proceso de paz, seguridad jurídica y democracia.

\title{
LEGAL UNCERTAINTY IN FACE OF THE IMPEDIMENT FOR EXERCISING THE PUBLIC ACTION OF UNCONSTITUTIONALITY WITHIN THE SPECIAL PEACE PROCESS
}

\begin{abstract}
This research document seeks to identify to what extent the legislative acts issued under the special peace procedures generate legal certainty, considering that its constitutional control is performed only for procedural flaws in its formation and sua sponte, without allowing citizens to pursue the public action of constitutionality. For this reason, the legal nature of these mentioned legislative acts must be established, and also determine the constitutionality process, as stipulated by the Constitutional Court. In addition, it is evidenced that this legal imbalance has a solution through the different types of decisions the constitutional court can issue, for the purpose of exercising material and formal control over the reforming acts. In this particular case, issuing a judgment that interprets and makes an addition to the implementation of the peace agreement, with the purpose of ensuring the primary constitutional power and the participatory democracy as a fundamental characteristic of a democratic and constitutional social rule of law.
\end{abstract}

Keywords: Constitutional control, legislative act, peace process, legal certainty and democracy. 


\section{INSEGURANÇA JURÍDICA PERANTE O IMPEDIMENTO DO EXERCÍCIO DA AÇÃo PÚBLICA DE INCONSTITUCIONALIDADE DENTRO DO PROCESSO ESPECIAL PARA A PAZ}

\section{Resumo}

Este trabalho de pesquisa pretende identificar em que medida os atos legislativos que são expedidos sob o procedimento especial para à paz, geram segurança jurídica, em favor de que seu controle de constitucionalidade só se realiza por vícios de procedimento em sua formação e de ofício, sem permitir que se possa incoar por parte do cidadão a ação pública de constitucionalidade; razão pela qual é necessário estabelecer a natureza jurídica de estes atos legislativos e determinar o processo de constitucionalidade, conforme ao estabelecido pela Corte Constitucional, assim mesmo, evidencia-se que este desequilíbrio jurídico tem solução através da emissão de diferentes tipologias de sentencias que pode realizar a Corte Constitucional, com o objetivo de exercer um controle material e formal sobre estes atos reformatórios, sendo no caso concreto a expedição de uma sentença que interprete e adicione a implementação do acordo de paz, com o propósito de garantir o poder constituinte primário e a democracia participativa como característica fundamental de um Estado social, constitucional e democrático de direito.

Palavras-chave: controle constitucional, ato legislativo, processo de paz, segurança jurídica e democracia. 


\section{Introducción}

La investigación se realiza con el ánimo de evidenciar la inseguridad jurídica que genera la restricción del control de constitucionalidad frente a los actos legislativos que son expedidos dentro del procedimiento especial para la paz, el cual se ha denominado fast track, ya que este se limita a que su control se realice solamente por vicios en la formación del procedimiento, negando la posibilidad que el ciudadano ${ }^{1}$ ejerza la acción pública de inconstitucionalidad frente al surgimiento de dichos actos; por tanto, se hace notoria la vulneración del poder constituyente primario, ya que no se ejecuta un control amplio de estos actos, los cuales en muchos casos no se encuentran exentos de vicios en su contenido o en esencia ${ }^{2}$.

Así mismo, este artículo busca denotar las garantías que deben surgir dentro de un procedimiento especial para la paz, teniendo en cuenta que desde el punto de vista profesional fue necesario identificar la problemática, los alcances, lineamientos y soluciones que se establecen dentro de esta búsqueda.

No obstante, en el desarrollo de este documento se utilizó un método axiomático o deductivo, ya que para lograr los objetivos propuestos dentro de la investigación se establecieron los principios generales enmarcados en la Constitución Política ${ }^{3}$, con el fin de individualizar los quebrantamientos jurídicos que se propenden cuando se limitan derechos inherentes al ser humano, tal y como se observa dentro del contenido específico del literal $\mathrm{k}$ del artículo transitorio del acto legislativo $01 \mathrm{del}$ año 2016, conocido como fast track, el cual es expedido con el fin de implementar un acuerdo de paz estable y duradero dentro del marco constitucional.

Ahora bien, ¿para qué se pretende revelar dicho desbalance jurídico?, se revela con el ánimo que los principios, garantías y derechos de la Carta Política sean efectivamente aplicados, pues el descontrol al respecto suscitaría una fragilidad constitucional, la cual posiblemente sea aprovechada a beneficio de pocos, sin oposición

${ }^{1}$ En el marco de la temática del presente manuscrito es importante anotar que en la actualidad se cuestiona sobre la realización plena o parcial del Estado moderno, y relacionada con esta discusión se encuentra la implementación de la democracia y de la ciudadanía (Llano, 2017).

${ }^{2} \mathrm{Al}$ respecto es importante no olvidar que el presidencialismo colombiano pasa por una crisis de legitimidad que alcanza de lleno al Estado democrático, pues la independencia y el equilibrio de los otros dos poderes: la representación parlamentaria y la administración de justicia han llegado a ser una fachada vacía (Rodríguez, 2017, p. 80).

${ }^{3}$ Entiéndase por principios mandatos de optimización, por cuanto son normas que ordenan que algo sea realizado en la mayor medida de lo posible (Miranda, 2016). 
alguna; es por ello que se busca generar un precedente basado en la protección de la constitución dentro de este proceso, donde se pretende que la soberanía sea efectivamente aplicada por el pueblo como el preámbulo constitucional lo indica.

En consecuencia de lo anterior, el tipo de metodología utilizado dentro de esta investigación es de carácter cualitativa, en aras de que a través de cuestionamientos generales y recolección de datos referentes a una situación que actualmente se encuentra en auge, se define un planteamiento en el que se evidencia el choque que surge entre derechos constitucionales y un procedimiento especial, que busca garantizar un derecho fundamental. Es así como se constituye una problemática inmersa en una realidad social, la cual es narrada desde un punto de vista legítimo y activista, donde se contextualizan unos hechos de paz, que son descritos e interpretados con el ánimo de evaluar el ambiente en que se ha desenvuelto el acuerdo bilateral que surge entre el Estado colombiano y las Farc, y de lo cual nace la elaboración de un compendio que crea las medidas para establecer una paz estable y prolongada dentro de los principios y valores de la Carta Política.

Por lo tanto, a través de este tipo de metodología se pudo abarcar cada uno de los objetivos propuestos dentro de esta investigación y se identificó la naturaleza de las actuaciones, el proceso de constitucionalidad de los actos reformatorios, las tipologías de sentencias que puede emitir la Corte Constitucional con el fin de proteger la constitución y la inseguridad jurídica de los actos legislativos que nacen dentro de este proceso especial para la paz, logrando contextualizar las circunstancias de tiempo, modo y lugar que dan paso a la solución del problema de investigación a través de una paz constitucionalizada, e interpretada por la corporación encargada de ejercer la salvaguarda de dicho texto.

\section{Naturaleza jurídica de los actos legislativos emitidos como consecuencia del proceso de paz}

En el año 2010 inicia el proyecto de la paz, con el advenimiento de Juan Manuel Santos Calderón como presidente de la República de Colombia ${ }^{4}$, quien toma el riesgo de proponer nuevamente un diálogo con las insurgencias guerrilleras presentes

${ }^{4}$ Es importante no olvidar que a partir de la Constitución Política de 1991, Colombia pasó de un Estado legislativo a uno de constitucionalidad, en el que la Carta Superior, además de ser un pacto social, se erigió como una verdadera norma jurídica susceptible de aplicación directa (Revelo y Valbuena,2017). 
en el país, después de múltiples fracasos en la historia colombiana. Es así como se da inicio al proceso de paz en Colombia con el grupo guerrillero de las Farc.

Dentro del análisis de los procesos de paz en la etapa de reconstrucción posbélica, se hace necesario mencionar algunas áreas que hacen parte de las temáticas fundamentales, las cuales son promovidas dentro de los actos legislativos que nacen con respecto a esta etapa, como lo son: 1) el apoyo a la democratización, con un tema trascendental que es el auxilio en sistemas electorales; 2) la vigilancia sobre los derechos, en donde se debe realizar una difusión de Derecho Internacional Humanitario y ardua educación en cuanto a los derechos humanos; 3) el fortalecimiento del proceso de paz, con una impecable verificación de los acuerdos y la creación de comisiones de la verdad; 4) la desmilitarización, en donde se realiza trabajo en el desminado del territorio y en la reducción de los presupuestos militares; 5) el desarme, desmovilización y reintegración de excombatientes, con transferencias de tierras y capacitación para este grupo; 6) el apoyo al retorno de refugiados y desplazados por la violencia; 7) el apoyo a los heridos y las familias de las víctimas y finalmente 8) la rehabilitación de las zonas dañadas (Cultura de paz, 2010, p. 22).

En septiembre del 2012 el presidente de la República anuncia la terminación del acuerdo general con las Farc, que se gestó después de una fase exploratoria no pública, dicho acuerdo desarrolla una agenda donde se determinan los puntos a tratar en la siguiente etapa, como lo eran en su momento: el desarrollo agrario integral, la participación política, la terminación del conflicto, la solución de problemas de drogas ilícitas, las víctimas y finalmente la implementación y el seguimiento al acuerdo (Acuerdo final para la terminación del conflicto y la construcción de una paz estable y duradera, 2016).

Este acuerdo general dio paso a la segunda fase del proceso de paz colombiano, que fue la negociación, en este ciclo se acuerda el cese al fuego y hostilidades bilateral, por medio del comunicado del 26 de agosto del año 2012.

El gobierno nacional y las Farc-EP se comprometen con el cumplimiento de lo aquí acordado en materia de cese al fuego y de hostilidades bilateral y definitivo (CFHBD) y dejación de armas (DA), para lo cual elaboran una hoja de ruta que contenga los compromisos mutuos para que a más tardar a los 180 días luego de la firma del acuerdo final haya terminado el proceso de dejación de armas. (Acuerdo sobre cese al fuego y hostilidades bilateral y definitivo y dejación de armas entre el Gobierno y las Farc-EP, 2012, p. 2) 
Posterior a las negociaciones del 2012, y tras los cuatro años de diálogos de paz, en el 2016 se gesta el "Acuerdo final para la terminación del conflicto y la construcción de una paz estable y duradera”.

Una vez terminada la concertación, surge como reto la refrendación del acuerdo, que acordaron materializar el 23 de junio del 2016, acogiéndose al mecanismo de participación popular establecido en el proyecto de ley estatutaria n. ${ }^{\circ} 156 \mathrm{del}$ 2015, en la Cámara de Representantes n. ${ }^{\circ} 94$ del 2015, Senado (acuerdo sobre refrendación, 2016), ley estatutaria declarada exequible por medio de la sentencia de constitucionalidad 379 del 18 de julio del 2016 , en la cual se regula el plebiscito para la refrendación del acuerdo de paz.

Con el plebiscito del 2 de octubre del 2016, se evidencio la polarización del pueblo colombiano por los puntos acordados, con una votación de 50,21 \% en contra y 49,78 \% a favor (Registraduría Nacional del Estado Civil, 2016); los movimientos opositores al acuerdo de paz solicitaron en su momento la revisión del acuerdo y su posterior modificación. Una vez realizado el proceso democrático de los cambios requeridos por la ciudadanía estos se refrendaron por vía legislativa, obteniendo en el Senado 75 votos y en la Cámara de Representantes 130 votos, esto el 30 de noviembre del 2016.

Este proceso de paz por su naturaleza sui generis ha presentado problemáticas jurídicas, en busca de la aplicabilidad de todo lo acordado. Cuando en su génesis lo complicado era concertar, una vez logrado un acuerdo, se fueron presentando otro tipo de inconvenientes, es así como con posterioridad el tema que presentaba dificultad y en evidencia mucho análisis como lo es la refrendación. Finalmente, lo que hoy nos ocupa es interpretar la manera en que progresivamente se ha implementado el acuerdo, toda vez que este proceso exigía la adaptabilidad de la Constitución Política Colombiana.

Es así como se estudia la posibilidad de un acto legislativo, teniendo en cuenta que sus funciones son lograr modificar, adicionar o reformar la Constitución Política en torno a la realidad que se vive según la naturaleza de estos mismos, ya que se debe tener en cuenta que la facultad otorgada influye principalmente en la teoría del poder constituyente, "según la cual el pueblo o la nación tienen la facultad y capacidad de expedir y reformar la Constitución” (Cerra, 2004, p. 106).

${ }^{5} \mathrm{Al}$ respecto, es importante no olvidar que en Colombia "desde la concepción de las principales normas del Estado, se tienen aquellas que a la luz de los procesos principales han irradiado los ámbitos de las necesidades" (Cuervo y Márquez, 2017, p. 114). 
Teniendo en cuenta lo anterior, y en ocasión de mencionar las generalidades de los actos legislativos que fueron expedidos dentro del proceso especial para la paz, es preciso hablar de lo especifico de cada uno de estos.

El Marco Jurídico para la Paz, buscó producir un espacio legal en la Constitución Política colombiana, el cual permita la aplicabilidad del acuerdo con la guerrilla de las Farc, dando origen al acto legislativo 01 del 2012, "por medio del cual se establecen instrumentos jurídicos de justicia transicional en el marco del artículo 22 de la Constitución Política y se dictan otras disposiciones", que permite que se puedan determinar criterios de priorización y selección en la investigación penal. Su naturaleza jurídica consistió en los siguientes preceptos: generar garantías de no repetición; reconocer a la victimas los derechos de verdad, justicia y reparación, así mismo la creación de dos artículos transitorios en la Constitución Política; por último, en materia penal la suspensión de la pena o la instauración de penas alternativas para los actores del conflicto armado que se encontraran cobijados bajo este acuerdo.

La esencia principal de esta figura jurídica que buscó la adición constitucional ${ }^{6}$ se hizo en torno de la protección de las víctimas, bajo el entendido:

La Corte determinó que existe un pilar fundamental de la Constitución que consiste en el compromiso del Estado social y democrático de derecho de respetar, proteger y garantizar los derechos de la sociedad y de las víctimas. En virtud de este mandato, existe la obligación de: (i) prevenir su vulneración; (ii) tutelarlos de manera efectiva; (iii) garantizar la reparación y la verdad; y (iv) investigar, juzgar y en su caso sancionar las graves violaciones a los derechos humanos y al Derecho Internacional Humanitario. (Corte Constitucional, 2013)

Evidenciando de esta manera que dicho acto legislativo busco resarcir los perjuicios ocasionados a los civiles que no tenían nada que ver en el conflicto armado, pero dando la posibilidad del dialogo a través de una justicia restauradora.

Por otra parte, vale la pena preguntar cuál es la necesidad que nazcan a la vida jurídica los actos legislativos expedidos bajo el procedimiento especial para la paz y en especial el 01 del 2012, si bien es cierto es su principio buscaba generar garantías

${ }^{6}$ El ordenamiento jurídico colombiano debe estar sometido a la primacía de la Constitución Política. "Sin embargo, a partir de nuevos desarrollos teóricos y jurídicos en el orden internacional, la Corte Constitucional realiza un control abstracto y material sobre la subordinación formal y sobre los contenidos sustantivos de las normas, excluyéndolas del orden legal” (Camargo, 2016, p. 138). 
a las víctimas, también tenía la necesidad de implementar una justicia transicional; según Turegano (2013), esta es aquella donde:

Se abarca toda la variedad de procesos y mecanismos asociados con los intentos de una sociedad para resolver los problemas derivados de un pasado de abusos a gran escala, con el fin de que los responsables rindan cuentas de sus actos, sirvan a la justicia y logren la reconciliación y estabilidad política. (2013, p. 4)

En otras palabras, lo que se buscaba a través de esta figura era crear un instrumento que le facilite a la sociedad generar una situación de paz estable a través de la institucionalización, en donde las víctimas y sus victimarios deben ceder a la negociación en búsqueda de un acuerdo que beneficie a las dos partes inmersas dentro de este tipo de negociaciones.

Con posterioridad a este acto legislativo se gesta el acto legislativo 01 del 2016, "por medio del cual se establecen instrumentos jurídicos para facilitar y asegurar la implementación y el desarrollo normativo del acuerdo final para la terminación del conflicto y la construcción de una paz estable y duradera", que fue nombrado como el fast track, y el cual abre las puertas a la creación de un procedimiento especial, mucho más ágil que el ordinario, con la finalidad de darle mayor cobertura y aplicabilidad a las normas que se produzcan en razón al proceso de paz. En su esencia fue creado con varios objetivos que buscan la implementación de un procedimiento especial por un periodo de seis meses y prorrogable por otro igual; dentro de su naturaleza jurídica se encuentra que se le conceden facultades extraordinarias al Gobierno Nacional para que exclusivamente este sea quien emita los proyectos de ley y actos legislativos en pro de facilitar el derecho a la paz, así mismo se establece que el procedimiento para estas dos figuras jurídicas será diferente al ordinario, debido a que los actos legislativos serán tramitados en una sola vuelta de cuatro debates, dentro de este también se efectúan censuras en cuanto al poder originario del constituyente, tal y como lo establece dicho acuerdo.

Es por ello que se debe indicar que este acto legislativo fue establecido con el ánimo de implementar dentro del marco constitucional las circunstancias de tiempo, modo y lugar que afronta el país, siendo tan importante este que el "Gobierno cuenta con la posibilidad de objetar regulaciones expedidas por el Congreso que tengan por objeto negar o destruir el acuerdo" (Corte Constitucional, 2017); dicho en otras palabras, se le concede al ejecutivo la facultad de defender el acuerdo del 
procedimiento especial para la paz, en aras de que se priorice lo que se acordó en las negociaciones de la Habana.

Este acto legislativo mediante el cual se busca implementar el procedimiento especial para la paz, tiene la finalidad de buscar la reforma de la Constitución Política, aunque sus efectos en tiempo son limitados "solo puede proferirse dentro de un término de seis meses siguientes a su entrada en vigencia, prorrogable por un periodo igual. Por lo mismo, una vez vencido ese plazo desaparece el mecanismo especial de reforma" (Corte Constitucional, 2016). Teniendo en cuenta esto se denota que dicha actuación cambia procedimientos de la rama legislativa, con el fin de conceder garantías al poder ejecutivo para que pueda llevar a cabo la misión e implementación al cese del conflicto armado en Colombia.

En consecuencia, la naturaleza jurídica de los actos legislativos tramitados dentro del proceso especial para la paz, no es otra distinta a la creación de espacios jurídicos dentro de la legislación colombiana para la aplicabilidad de los acuerdos de la Habana con las Farc-EP.

En resumen de lo que se ha expresado, vale la pena decir que bajo la anhelada paz que se ha querido para Colombia, se han ejecutados dos eventos jurídicos importantes, siendo estos los actos legislativos 01 del 2012 y 01 del 2016, el primero creó medidas de reparación para las víctimas del conflictos armado, de verdad, justicia, reparación y no repetición, en materia penal buscó la amnistía judicial o mecanismos alternativos a la pena; por otro lado el acto legislativo del2016, crea un proceso especial y diferente al ordinario para el trámite de leyes, decretos ley y actos legislativos, concede la exclusividad de la expedición de estas figuras al Gobierno Nacional, y por último restringe el uso de la acción pública de institucionalidad del ciudadano frente a la objeción de los actos legislativos que se expiden bajo el proceso especial del posconflicto.

\section{Proceso de constitucionalidad ${ }^{7}$ en los actos legislativos que son expedidos bajo el procedimiento especial para la paz}

De conformidad con Aldana y Guarín (2016), con la creación de la Corte Constitucional en 1991, la balanza del poder se ha venido inclinando de manera

${ }^{7}$ Para el efecto, el control de constitucionalidad debe de ser entendido como garantía jurisdiccional de la función legislativa (Forero, 2016). 
acentuada en favor de la rama judicial ${ }^{8}$. Bajo el amparo de su doble misión de guardián de la integridad y supremacía de la Constitución Nacional y de administrador de justicia. El alto tribunal de lo constitucional ha ampliado el espectro de su competencia y ha asumido una posición prevalente frente a las demás ramas del poder público, haciendo suyas algunas funciones que no le son propias, lo cual ha generado conflictos entre ellas.

Con la Constitución Política de 1991, los procesos de constitucionalidad gozaron de una efectividad plena, el artículo 241, numeral 1, le concedió a la Corte Constitucional la guarda e integridad de la Carta Política, con el fin último de que esta se encargara de hacer efectivos cada uno de los derechos y deberes nominados dentro de este compendio, decidiendo sobre las demandas de inconstitucionalidad que son promovidas por los ciudadanos, para que de esta manera se realice el estudio por vicios de procedimientos en la formación de aquellos actos que buscan reformar dicho texto:

No obstante, se indica que el control de constitucionalidad es el conjunto de instituciones y de procedimientos destinados a hacer efectiva la supremacía de la Constitución, a realizar el carácter normativo de la misma, a garantizar la vigencia y efectividad de los derechos fundamentales de las personas dentro del Estado, así como a permitir la realización de reglas, principios, valores e instituciones propias del Estado Constitucional democrático. (Quinche, 2015, p. 21)

Abarcado de una manera general lo referente al control constitucional, se manifiesta que en Colombia existe el constituyente originario y este se encuentra en manos del pueblo, quien es el que en primer lugar goza de la facultad de reforma de la Carta Política, y el constituyente derivado que es la corporación que estudia dichas reformas, por tal motivo se debe evidenciar si los actos legislativos reformatorios que son expedidos bajo el procedimiento especial para la paz pueden ser objetados por el constituyente originario, y así mismo si su estudio de constitucionalidad puede realizarse no solamente por vicios de procedimiento en su formación, sino también por vicios materiales o de fondo con el pretexto de que no se limite el poder a una plena revisión.

${ }^{8}$ De conformidad con Guarín (2016), "en los Estados jurisdiccionales, dada la forma como los jueces concentran el poder, se genera una desnaturalización de la función judicial que afecta la recta administración de justicia y, con ello, al bien común” (p. 14). 
En lo mencionado, hay que indicar que existen dos modos de activar el control judicial de constitucionalidad que ejerce la Corte Constitucional en la revisión de los actos que son estudiados, primero se habla de un control rogado que es aquel en el que un ciudadano solicita revisar la constitucionalidad de una norma a través de la acción pública de inconstitucionalidad, segundo de un control automático en el que la Corte Constitucional de oficio realiza el estudio de un decreto ley, de un acto legislativo, o de leyes.

Con respecto de los vicios del procedimiento, en la formación se indica que estos ocurren cuando hay desconocimiento de los principios constitucionales que se indican en el procedimiento legislativo, ya que:

\section{El objeto de dicho control es determinar si al llevar a cabo un trámite legislativo se presentaron diferencias entre lo ocurrido en la realidad y lo que las normas pará- metro de control exigen que ocurra en desarrollo de dicho procedimiento. (Corte Constitucional, 2011)}

Por otro lado, se evidencia que existe el control material o de fondo quien es el que se encarga de evaluar el contenido de las figuras jurídicas presentadas con el ánimo de crear una ley, modificar o adicionar a la Carta Política, el cual no es aplicable para los actos legislativos, toda vez que como es evidente, estos van a ir en contra de la Carta Política, debido a que su pretensión es la modificación normativa de esta.

Como se evidencia, la Constitución Política de 1991 no cuenta con la figura de protección constitucional contemporánea como lo son las cláusulas pétreas o inmodificables, sin embargo, la Constitución colombiana al permitir su reforma mas no su sustitución, impone unos límites, con el fin de proteger la esencia de la Carta: "el poder de reforma tiene límites competenciales, pues no puede sustituir la Constitución de 1991" (Corte Constitucional, 2003), además esta protección la materializa con el procedimiento especial que requiere una ley u acto reformatorio, con determinado número de debates, mayorías absolutas y términos más extensos.

Abarcando el tema principal, es menester hablar sobre el control de constitucionalidad que se ejerció sobre los actos legislativos 01 del 2012 y 01 del 2016, los cuales fueron expedidos bajo el procedimiento especial para la paz en su determinado momento, el primero estableció un parámetro general que consiste en que a pesar de que a la corporación que se le da la salva guarda de la Constitución, le ocupan límites de su control de constitucionalidad y "tiene competencia para verificar el 
proceso de formación y es su obligación guardar la integridad y supremacía de la Carta, puede declarar la inconstitucionalidad de una reforma constitucional por vicios de competencia" (Corte Constitucional, 2013), con el fin de que a través de esta figura jurídica con la cual se busca la reforma de la Carta Política no se sustituya esta.

Así mismo a lo referido en el acto legislativo 01 del 2016, lo que se buscó fue generar un procedimiento especial, mucho más ágil, para el tratamiento de las leyes y reformas que sean necesarias para la aplicabilidad del proceso de paz. A partir de dicho acto, se crea un "procedimiento legislativo especial para la paz" que tendrá un término de 6 meses, prorrogables por otros 6 meses, gozan de las siguientes características, su control constitucional para los actos legislativos tramitados en el contexto del proceso de paz, es posterior y automático y en las leyes estatutarias se realizará un control previo.

$\mathrm{El}$ análisis que se realiza sobre estos solo se da por vicios de procedimiento en su formación, por otro lado se reducen los términos de la revisión para las leyes y actos legislativos a la tercera parte del procedimiento ordinario sin obtener prorroga alguna (Acuerdo final para la terminación del conflicto y la construcción de una paz estable y duradera, 2016, p. 277).

Referente a lo anterior, hay que indicar que a pesar de que estos actos legislativos son expedidos bajo el procedimiento especial para la paz, deben contar con un control que no delimite su estudio, en razón a que en diferentes ocasiones ha señalado la Corte Constitucional, que:

Dicho control no puede ejercerse únicamente desde el título XIII de la Constitución, por la sencilla razón que este título remite hacia otras normas constitucionales y a la ley 5 de 1992, orgánica del Congreso. De esta manera ha concluido que la expresión "solo" no puede ser interpretada de modo literal y exegético, pues de esa manera se desvirtuaría todo el sistema de control sobre las reformas constitucionales. (Quinche, 2014, p. 108)

Por tanto, al no aceptar que se realice dicho control por circunstancias materiales como procedimentales, es negar la esencia de la Constitución, ya que esta es la máxima expresión de democracia del pueblo (Hernández, 2009, p. 43).

Además se observa que el control de constitucionalidad ejercido por la Corte Constitucional en Colombia, es un mecanismo que busca prolongar la seguridad 
jurídica como fin esencial del Estado, tal y como lo ha venido manifestado la doctrina jurisprudencial de esta Corte, pues a partir del pronunciamiento dado en la sentencia C-551 del 2003, en la cual se hizo el control de constitucionalidad de la Ley 796 del 2003, se acogió la tesis de los límites competenciales del poder de reforma y la inconstitucionalidad por sustitución, en donde se determinó que debe probarse la vulneración de principios y valores. En cuanto a los actos legislativos, establece que se debe evidenciar que el órgano que expidió la reforma era el competente para hacerlo.

En este orden de ideas, y debido a que en este momento es la realidad que se vive en el país, se quiso hacer un análisis más profundo con respecto al acto legislativo 01 del 2016; la Corte Constitucional se pronunció haciendo un estudio de la demanda de inconstitucionalidad interpuesta por un ciudadano, que manifiesta su insatisfacción en cuanto al nuevo procedimiento especial para la paz, en donde se otorgan facultades extraordinarias al presidente de la República, para la expedición de decretos con fuerza de ley y la reducción de términos para el debate legislativo de leyes estatutarias y actos legislativos.

De esta manera la Corte Constitucional establece que tratándose del momento histórico, la necesidad de la aplicabilidad de dichos acuerdos y por la dinámica que es permitida en la Carta Política, es aceptable la creación de un procedimiento especial y, además que por tratarse de procedimiento especial transitorio, no estaría modificando la Constitución Política Nacional, ya que después de terminado este término de 6 meses posiblemente prorrogable por otros 6 meses, la Constitución y en especial el procedimiento legislativo será nuevamente el ordinario, sin importar que se trate de leyes u actos legislativos en el contexto del proceso de paz en Colombia; reafirmando de esta manera que el acto legislativo 01 del 2016 de ninguna manera atenta contra los principios constitucionales de la Carta Política colombiana de 1991, es por tal motivo que no se genera una sustitución constitucional, dándole total aplicabilidad al acto legislativo en mención?.

${ }^{9}$ Los actos legislativos especiales, fruto del acto legislativo 01 del 2016: (i) son proferidos en virtud de un procedimiento de reforma especial (pues su objeto es la transición hacia la terminación del conflicto), excepcional (solo para implementar el acuerdo) y transitorio (solo por 6 meses, prorrogables por un periodo igual); (ii) tienen por objeto facilitar y asegurar la implementación del acuerdo final para la terminación del conflicto, mas no excluyen que la implementación de un acuerdo final pueda adelantarse por un procedimiento distinto; (iii) solo pueden surtir su etapa parlamentaria, si hay una refrendación popular del acuerdo final, en los términos señalados; (iv) deben tener iniciativa exclusiva del Gobierno Nacional; (v) tienen siempre trámite preferencial y prioridad en el orden del día; (vi) deben tener un título especial, conforme al cual se aclara que en virtud de la reforma cuestionada "el Congreso 
Por lo tanto, el procedimiento constitucional de los actos legislativos expedidos dentro del proceso especial para la paz con la guerrilla de las Farc, cuentan con un control constitucional posterior, automático y único; solo podrá realizarse sobre los vicios de procedimiento en su formación y serán tramitados en una sola vuelta de cuatro debates, siempre y cuando se encuentre vigente el término establecido dentro del acto legislativo 01 del 2016 para los procedimientos legislativos especiales para la paz.

\section{3. ¿La Corte Constitucional a través de las diferentes tipologías de sentencias, puede ejercer control de constitucionalidad material y formal de los actos legislativos?}

El Estado colombiano ha sido catalogado como un Estado social constitucional y democrático de derecho, con esta renuencia la evolución y el acople de un sistema meramente positivista o exegético, a un sistema anglosajón se ha visto como uno de los pilares principales en la búsqueda de la protección y salvaguarda de la Constitución Política, pues se evidencia que a través de la funciones asignadas a la Corte Constitucional a partir del año 1991, esta ha venido creando derecho por medio de lo que se conoce como activismo judicial, en donde a través de las diferentes tipologías de sentencias que ha emitido esta corporación y mediante sus decisiones, crea un precedente judicial con el ánimo de proteger derechos fundamentales.

Por lo tanto, y en el tema que corresponde, es preciso hablar sobre las diferentes tipologías de sentencias que ha dirimido la Corte Constitucional con respecto a los estudios de constitucionalidad de los actos legislativos; frente a este tema menciona Olano (2004), que existen veintiún tipos de sentencias de la Corte Constitucional, las cuales se encuentran sistematizadas en seis clases de modulaciones, estas clases son: modulación tradicional, modulaciones o sentencias manipulativas, modulaciones relativas al efecto temporal o prospectivas,

de Colombia, en virtud del procedimiento legislativo especial para la paz, decreta”; (vii) se tramitan en una sola vuelta de cuatro debates y ocho días de tránsito entre las Cámaras; (viii) en esos cuatro debates el proyecto se aprueba con mayoría absoluta; (ix) solo pueden experimentar modificaciones los proyectos cuando se ajusten al contenido del acuerdo final y tengan aval del Gobierno; (x) pueden tramitarse en sesiones extraordinarias; (xi) tienen control constitucional automático (sentencia C-699 del 2016). 
modulaciones del derecho de los jueces, otros módulos sin modulación y por último los modelos específicos (pp. 572-573).

Las tipologías de sentencias se generan con el ánimo de que "la corte, usando la libertad de determinar por sí misma el efecto de sus sentencias, introdujo una teoría más o menos comprehensiva de modulación de los efectos de las sentencias tipo 'C'” (López, 2016, p. 54), buscando con ello una apreciación de la realidad, implícita y objetiva frente a las circunstancias de cada estudio.

Con respecto a la temática señalada sobre el control de constitucionalidad de los actos legislativos, se abarcarán los modelos sin modulación y las sentencias manipulativas, a pesar que en esta subdivisión se ubican varios tipos de sentencias, es preciso realizar el estudio sobre aquellas que pueden dar solución a la ejecución de un control formal y material de los actos reformatorios; por tanto las primeras son las que se ocupan de indagar sobre el control que se realiza frente a esta figura jurídica, siendo estas las sentencias del control concreto de constitucionalidad, las segundas son aquellas que sustituyen, adhieren o integran, siendo estas las sentencias integradoras o aditivas. Así mismo se encuentran las sentencias sustitutivas y las interpretativas o condicionales, tal como lo ha manifestado reiteradamente el jurista Olano.

Al hablar de las sentencias de control concreto de constitucionalidad se hace referencia a aquellas que estudian el cumplimiento de los preceptos y principios que enmarca la Constitución Política, generando de esta manera un control formal, dentro de la expedición de leyes o actos legislativos que esgrimen o no la constitucionalidad con el fin de que se declare si los instrumentos materiales de estudio trasgreden o no la Carta Política; por otro lado, ha indicado Alcalá (2004) lo siguiente:

La sentencia de un Tribunal Constitucional más que un acto procesal que pone término a un conflicto jurídico, como ocurre con las sentencias de los tribunales ordinarios de justicia, es además una decisión con trascendencia política, ya que realiza una labor de interpretación de valores y principios y una actividad integradora del derecho.

Por tanto, este tipo de sentencias se enfocan en verificar el cumplimiento de las garantías constitucionales. 
Por otro lado encontramos las sentencias declarativas de inconstitucionalidad, estas son aquellas en las que se precisa si es incompatible o no la norma con la carta fundamental, y se le otorga al legislador la oportunidad de modificar o corregir la norma que fue declarada inconstitucional, dejando activa la posibilidad de que se efectúen las correcciones (Olano, 2004, p. 589).

Por consiguiente, hay un segundo grupo de tipología de sentencias que son las aditivas, sustitutivas e interpretativas. Las sentencias aditivas, no anulan la disposición que fuese acusada, sino que por el contrario, entran a agregar contenido para que de esta manera sean constitucionales; muchas veces incorporan un elemento nuevo para que asuma un supuesto de hecho no contemplado en sus inicios (Martínez, 2000, p. 19).

Las características de las sentencias aditivas tienen dos modalidades: la primera es cuando se presenta una omisión normativa y es considerada por la Corte Constitucional como una laguna jurídica, que es finalmente cubierta por su labor interpretativa; la segunda es cuando dicha omisión es considerada como una exclusión, por lo que la eliminación de la omisión implica incluir a aquellos que habían sido marginados o discriminados arbitrariamente (Nogueira, 2004, p. 21).

Por la complejidad de la aplicación de este tipo de sentencias generalmente a modo de protección, el Tribunal o la Corte Constitucional dirimen la controversia pronunciándose por medio de su poder de discrecionalidad, "cuando a la corte se le requieren decisiones de este tipo, aditivas o sustitutivas, son frecuentes los pronunciamientos de inadmisibilidad por discrecionalidad del legislador" (Groppi, 2003).

Este tipo de sentencias son de difícil aplicabilidad para la Corte Constitucional o para quien haga sus veces, debido a que en muchas ocasiones se confunde el activismo judicial de la corporación, con el abuso de competencias, sin evidenciar que este se da con el fin de subsanar una comisión legislativa.

Tenemos las sentencias integradoras sustitutivas, por medio de las cuales la corte propulsa del ordenamiento jurídico una disposición porque se cree contraria a la Carta Política, y sustituye esta, buscando que de dicha manera no se presenten vacíos jurídicos, ya que la Corte Constitucional manifiesta lo siguiente: "son una modalidad de decisión por medio de la cual el juez constitucional proyecta los mandatos constitucionales en la legislación ordinaria, para de esa manera integrar aparentes vacíos normativos o hacer frente a las inevitables indeterminaciones del orden legal" (2009), buscando que con ello se propaguen las garantías constitucionales. 
En consecuencia, y con mayor atención por la conexidad con el tema que estamos analizando y el cual surge en torno al procedimiento especial para la paz, es preciso establecer las características básicas de las sentencias interpretativas, en este tipo de sentencias se restringe el alcance normativo, ya que las disposiciones que son acusadas pueden ser expulsadas del ordenamiento jurídico, sin querer decir que se pierda la eficacia de la misma (Olano, 2004).

En este orden de ideas el control constitucional que realiza la Corte Constitucional referente a Colombia es "en la sentencia interpretativa, escoger la interpretación constitucionalmente correcta como válida y la aplica, señalando que elegir las interpretaciones alternativas conducirán a la declaración de inconstitucionalidad, desde luego, en la aplicación de la norma” (Altuve, 2010, p. 166).

Como bien sabemos, y entrando en el tema competente de la investigación, la Corte Constitucional estableció que el procedimiento especial para la paz tiene un carácter transitorio, no modificatorio de la constitución, pues después del término de 6 meses prorrogables por un término igual, la Constitución sigue idéntica, de modo tal que las leyes y actos legislativos posteriores a este término se realizan por el procedimiento ordinario, sin importar si se está en contexto del proceso de paz, razón por la cual se hace evidente que no hay una comisión legislativa, sino que dentro de la función de control constitucional, dicho órgano puede delimitar la interpretación del acto legislativo 01 del 2016 con la finalidad de evitar que se atente contra los principios constitucionales y haya un desbordamiento del poder ejecutivo, en razón de los poderes excepcionales que le fueron concedidos con dicha normatividad al Gobierno Nacional.

En este orden de ideas, y con el fin de establecer cómo la Corte Constitucional colombiana puede por medio de la tipología de sentencias realizar un control constitucional material y formal en los procedimiento de los actos legislativos referentes al contexto del proceso de paz, en consecuencia que este se limita para el ciudadano según lo establecido en el literal k del artículo 1 transitorio del fast track, se puede concluir que mediante las sentencias interpretativas, es decir, que por medio de estas se delimite la interpretación del acto legislativo 01 del 2016, y así mismo se hace posible integrar las omisiones legislativas del proceso especial para la paz, evitando una interpretación contraria a los principios, valores o normas de la Constitución.

A causa de lo enunciado en este literal, y habiendo explicado grosso modo la función de cada tipo de sentencia, es preciso indicar que en el tema que nos concierne y el cual se ha venido tratando como el procedimiento especial para la paz, 
se indica que hay un control automático y único frente a la expedición de dichos actos, como se ha reiterado por medio de esta temática, observándose que de esta manera se crean restricciones al poder originario en harás de que ningún ciudadano podrá interponer la acción pública de inconstitucionalidad solicitando el estudio de ellos, por tanto, a pesar de que la Corte Constitucional ya realizó un control de oficio a través de la sentencia de constitucionalidad 699 del 2016 en donde esta cooperación analizó los artículos 1 y 2 de este acto legislativo, por lo que se denota que frente a estos hay un estudio que hace tránsito a cosa juzgada absoluta con respecto a la situación que indica el actor.

Teniendo en cuenta el párrafo anterior, en dicha demanda no se solicitó la inconstitucionalidad del literal k, por tal razón frente a esta no hay una decisión absoluta sino relativa, bajo el entendido que el mecanismo adecuado es una sentencia aditiva en donde debe adherírsele al acto refrendatorio, la posibilidad de que los ciudadanos puedan ejercer el derecho de acción, entendiendo que la soberanía recae en el pueblo y la soberanía no es más que el grito de democracia que impartió la constituyente del 91, así mismo a través de una sentencia interpretativa se debe aclarar dicho texto, con la finalidad de salvaguardar la esencia de la Constitución.

Por lo anterior, hay que realizar un breve recuento de lo que es en una sentencia, la cosa juzgada constitucional absoluta, y la cosa juzgada relativa, frente a esto indica la Corte Constitucional lo siguiente:

Será cosa juzgada absoluta, cuando la primera decisión agotó cualquier debate sobre la constitucionalidad de la norma acusada. Será cosa juzgada relativa si la Corte en una decisión anterior juzgó la validez constitucional solo desde la perspectiva de algunos de los cargos posibles. (2016)

Por ello hay que indicar que cuando hay cosa juzgada absoluta no se puede impetrar nuevamente la solicitud de examen constitucional, mientras que en el segundo caso se puede solicitar dicho estudio por nuevas acusaciones; por consiguiente, hay que indicar que dicha figura jurídica no busca que a través de la tipología de sentencias se ejerza una retroactividad a una decisión que ya fue tomada, pero con el ánimo de que dentro de esta se garanticen los principios fundamentales e intrínsecos de la Carta Política, la aclaración e interpretación del texto debe ser definida para que no se generen vacíos jurídicos, sino por el contrario se constituya una garantía judicial y fundamental para el ciudadano. 


\section{4. ¿Se genera acaso inseguridad jurídica cuando bajo el procedimiento especial para la paz, se expiden actos legislativos que solo gozan de control constitucional por vicios en su formación y no en su contenido material?}

Para abarcar este capítulo debemos indagar en primer lugar qué es la seguridad jurídica, cuál es la razón esencial de ella, cuáles son sus características principales, qué importancia tiene esta en el Estado social constitucional y democrático de derecho en Colombia, el papel que cumple bajo los parámetros del proceso especial para la paz, y por último la finalidad que esta tiene en la actividad legislativa, con el ánimo de evidenciar si se transgrede la Constitución Política cuando no se realiza un control constitucional formal y material a los actos legislativos que son expedidos bajo las circunstancias especiales de transición que se encuentra viviendo en este momento el país.

La seguridad jurídica es un principio valor, que es esencial en cualquier Estado, puesto que este genera confianza, certeza y legitimidad frente a cada una de las actuaciones de la administración pública y los ciudadanos, ya que "en una sociedad como la nuestra, en la que tanto la ciencia como la técnica - y desde luego la praxis - dan continuas muestras de incertidumbre" (Luna, 2015, p. 23); este principio es fundamental para que haya una confianza legítima, en la que los derechos, deberes y garantías se cautelen y atiendan, bajo los parámetros de prevalencia y primacía.

Es preciso referirnos con importancia al filósofo Siches (1986), citado por Alterini (1993, p. 20), quien indicó que "sin seguridad jurídica no hay derecho, ni bueno, ni malo, ni de ninguna clase”, por ende se constata de esta forma que la seguridad jurídica es el propulsor de que nazca un derecho, el cual debe permanecer en el tiempo, con el ánimo de crear situaciones estables, que si bien es cierto deben adaptarse a la realidad a la que por evolución nos vemos expuestos, no es menos cierto que no se pueda dejar a un lado el hecho de que las garantías prevalezcan en el tiempo con la actividad de mejoría y no de recorte hacia ellas.

Cuando se hace referencia a la importancia de este principio valor dentro del Estado social constitucional y democrático de derecho, hay que referir a la Constitución como primer término, puesto que este principio se proporciona cabalmente 
en ella, debido a que "la seguridad jurídica es un principio que atraviesa la estructura del Estado de derecho y abarca varias dimensiones. En términos generales supone una garantía de certeza. Esta garantía acompaña otros principios y derechos en el ordenamiento" (Corte Constitucional, 2012), por lo tanto, es un principio inherente a la persona dentro del Estado, ya que de esta manera se le garantiza cada uno de los derechos, deberes, garantías y principios que son constituidos dentro de la Carta Política, con el fin de que en ningún momento se genere el antónimo de seguridad, y el que se puede ocasionar en el ordenamiento legal y constitucional cuando sus criterios y lo que se encuentra en ello consignado no se cumpla como se ha establecido.

Así mismo hay que hablar de las características generales de este valor principio, pues una de estas es la publicidad, ya que los ciudadanos conocen el contenido de sus derechos y obligaciones, además hay que indicar que este no es un valor autónomo pues siempre está respaldando a otro, tanto así que la seguridad jurídica se encuentra ligada a la buena fe, artículo 83 de la Constitución Política, y con esto a la confianza legítima que esta proporciona (Corte Constitucional, 2001).

Por otro lado, es de indicar que bajo el tema que nos compete, que es el papel que esta cumple frente a los nuevos presupuestos de la paz, bajo la implementación del proceso especial para una paz estable y duradera, este tema se vuelve sensible para la sociedad colombiana, ya que requiere la utilización de inteligencia colectiva con la finalidad de educar el proceso de paz colombiano al sistema democrático y constitucional característico de nuestro país.

De esta manera se evidencia que aun el acto legislativo 01 del 2016 ha gozado de varios análisis constitucionales, siendo el más reciente el de mayo del 2017, en los que todavía se detectan vacíos, pues es evidente que la Corte Constitucional aún no se ha pronunciado sobre cada uno de los lineamientos del fast track.

Si bien la Corte Constitucional por medio del control rogado se pronunció de fondo en artículos parciales del acto legislativo 01 del 2016, con posterioridad a esta interpretación por medio del control oficioso de constitucionalidad que realiza de uno de los decretos ley emitidos por el presidente de la República, en uso de las facultades conferidas por el artículo segundo transitorio del acto legislativo en mención, realiza un análisis exhaustivo determinando la inexequibilidad de algunos apartes de la norma, pero aun así sin un pronunciamiento total.

Por tanto, respecto al tema que nos corresponde, siendo este la imposibilidad de ejercer un control rogado de constitucionalidad, por medio del cual el ciudadano 
incoe la acción pública de inconstitucionalidad en contra de los actos legislativos expedidos dentro del contexto del procedimiento especial para la paz, la Corte Constitucional se ha declarado inhibida, tal como lo manifiesta el comunicado n. ${ }^{\circ}$ 28 de mayo del 2017, realizado por la corporación con el fin de dar conocimiento a las generalidades que han sido estudiadas en la sentencia C-332 de 2017, evidenciándose de esta manera la ausencia de pronunciamiento de la Corte Constitucional respecto del tema que hoy nos convoca.

Es por ello que este proceso debe ahondar cada lineamiento con el propósito que la certeza, la confianza legítima y la buena fe, sean los parámetros para garantizar una seguridad jurídica estable y continua en búsqueda de que se implemente una paz verdadera, y sin que esta sea la excusa para la vulneración de otros derechos contenidos en la Constitución Política colombiana.

\section{Conclusiones}

Globalmente este documento buscó ahondar sobre la inseguridad jurídica que se genera sobre los actos legislativos tramitados mediante el procedimiento especial para la paz, en el entendido que su control de constitucionalidad solo se realiza de oficio, y en este solamente se estudian los vicios de procedimiento en su formación, por tanto, diremos que:

En la investigación realizada se buscó contextualizar cada una de las etapas por las cuales ha pasado el proceso de paz; vale la pena decir que la paz como derecho fundamental ha sido una realidad deseada por nosotros los colombianos, ya que de esta manera la participación en la política no estaría restringida para el conglomerado de la ciudadanía, sino al contrario, se darían nuevos espacios de participación ciudadana en el que todos los colombianos podemos ser parte, esto con el ánimo de ejercer la defensa constitucional.

Se denota que Colombia ha estado inmersa en dos etapas especiales de transición que han sido de suma importancia para la historia del país, la primera fue en el año 2012, y la segunda la estamos viviendo en la actualidad, a pesar que durante este contexto se observan varias falencias jurídicas, como lo son las limitantes que se establecen frente al poder constituyente para que ningún ciudadano en ejercicio de la acción pública de inconstitucionalidad pueda ejercer la salvaguarda de la Constitución; también es cierto que estamos de acuerdo con el perdón, la reparación, reconciliación y no repetición de los actos violentos que 
han desangrado nuestra sociedad, sin embargo, enfatizando que queremos que no se nos desconozcan los principios democráticos por los que hemos luchado por más de cincuenta años, y los cuales se hicieron verídicos a partir de la Carta Política del año 91.

Es preciso decir que con respecto al acto legislativo 01 del año 2016, conocido coloquialmente como fast track este no está acorde con el marco constitucional, pues los principios, garantías, derechos y deberes constitucionales no pueden ser limitados por el hecho de que se cree un proceso especial para la paz, antes con el fin de garantizar la seguridad jurídica de un Estado social constitucional y democrático de derecho, se debe propender a que no se desconozcan estos atributos inherentes del pueblo, pues de esta manera no solamente se estaría vulnerando la Constitución Política sino el fin principal del Estado que es la democracia participativa.

Concluyendo, hay que indicar que se pudo establecer a lo largo de la investigación que los actos legislativos expedidos bajo el procedimiento especial para la paz no gozan de una seguridad jurídica plena, ya que a dichos actos reformatorios no se les puede realizar un control constitucional amplio, en el que no solo la Corte Constitucional de oficio intervenga, sino que el ciudadano a través de un control rogado también pueda hacerlo, teniendo en cuenta que solo se ejecuta un estudio por vicios de procedimiento en su formación, dejándose a un lado el análisis por vicios sustanciales y de contenido, ya que de no ejercerse plenamente esta figura no se garantizaría la primacía de todo el sistema de control constitucional que se ha realizado en anteriores reformas constitucionales.

En definitiva y con el fin de determinar una solución, se logra establecer que es posible la enmendación de estas falencias, por medio del uso de las tipologías de sentencias por parte de la Corte Constitucional, ya que mediante las sentencias interpretativas se puede delimitar la exégesis del acto legislativo 01 del 2016, puesto que esta permite integrar las omisiones legislativas del procedimiento especial para la paz, evitando que se vulneren los principios, valores, y normas contenidas en la Constitución Política, de la misma manera las sentencias aditivas, que consideran la omisión como una exclusión, permitiendo que a través de esta se ejecute un pronunciamiento que incluya aquellos derechos que han sido marginados de la norma en su génesis, es así como por medio de estas tipologías, la Corte Constitucional puede incluir el control rogado, en el que el ciudadano común queda facultado para incoar demandas de inconstitucionalidad contra los actos legislativos emitidos dentro del procedimiento espacial para la paz. 
En resumen, es preciso indicar que nuestro documento no busca identificar críticas que desvirtúen el anhelo de la paz, antes consideramos que al garantizar que dentro de ella los derechos constitucionales de los ciudadanos se efectúen de una manera amplia y democrática, se denotará seguridad y eficacia en la implementación total de este, con el ánimo de propender la inclusión de dicho acuerdo dentro del marco legal y constitucional.

Para finalizar hay que indicar que se ha emitido la sentencia de constitucionalidad C-332 del 2017, con respecto al literal $\mathrm{k}$ del artículo primero, artículo transitorio del acto legislativo 01 del 2016, quien en su decisión se ha inhibido con respecto al pronunciamiento sobre este, sin embargo, ha marcado una brecha en la que ha indicado que si no se demuestra que con este acto legislativo se sustituye la Constitución Política no existe la posibilidad de incoar la acción pública de inconstitucionalidad por parte del ciudadano, ya que no se darían argumentos válidos para proceder a esta, por otro lado, dentro de su ponencia manifiesta que el poder constituyente está erradicado en el pueblo, quien tiene y conserva la potestad de darse una Constitución, empero este poder constituyente originario no está entonces sujeto a límites jurídicos, y comporta, por encima de todo, un ejercicio pleno de poder político de los asociados, por tanto es menester indicar que en alusión a lo que literalmente manifiesta la Corte, es preciso que dicha corporación a través de la tipología de sentencias que anteriormente se indicaron en el presente artículo científico, ilustre el literal $\mathrm{k}$ de este acto legislativo, bajo el entendido de que el poder político del constituyente originario es pleno, y no está sujeto a restricciones jurídicas. 


\section{Referencias}

Alcalá, H. (2004). Consideraciones sobre las sentencias de los tribunales constitucionales y sus efectos en América del Sur. Ius et Praxis, (10). ISSN: 0718-0012.

Aldana, J., y Guarín, E. (2016, enero-junio). Los límites de la teoría del equilibrio como alternativa de solución a la cuestión de la prevalencia del poder del Alto Tribunal de lo Constitucional en Colombia. Revista Via Inveniendi et Iudicandi 11(1), 59-82. Recuperado de http://revistas.usantotomas.edu.co/index.php/viei/article/view/2923/2796

Alterini, A. (1993). La inseguridad jurídica. Buenos Aires, Argentina: Editorial Artes Gráficas Candil S.R.L.

Altuve-Febres, F. (2010). El juez constitucional como Legislador Positivo en el Perú. Revista Jurídica Piélagus, 9 (1), 159-175. doi:http://dx.doi.org/10.25054/16576799.618

Camargo, E. (2016, julio-diciembre). Positivismo, derecho y justicia en la Constitución Colombina de 1991. Revista Republicana, (21), 137-158. Recuperado de http://ojs. urepublicana.edu.co/index.php/revistarepublicana/article/view/333/302

Cerra, L. (2004). La Constitución no es el límite impugnación de actos legislativos los límites del poder constituyente. Revista de Derecho, (22), 105. Universidad del Norte, Recuperado de http://www.redalyc.org/articulo.oa?id=85102204

Corte Constitucional de Colombia. (9 de agosto del 2001). Sentencia C-836/01. M.P. Rodrigo Escobar Gil.

Corte Constitucional de Colombia. (9 de julio del 2003). Sentencia C-551/03. M.P. Eduardo Montealegre Lynett.

Corte Constitucional de Colombia. (13 de mayo del 2009). Sentencia C-325/09. MP. Gabriel Eduardo Mendoza Martelo.

Corte Constitucional de Colombia. (19 de septiembre del 2011). Sentencia C-685/11. M.P. Humberto Antonio Sierra Porto.

Corte Constitucional de Colombia. (28 de marzo del 2012). Sentencia C-250/12. M.P. Humberto Antonio Sierra Porto.

Corte Constitucional de Colombia. (28 de agosto del 2013). Sentencia C-579/13. M.P. Jorge Ignacio Pretelt Chaljub.

Corte Constitucional de Colombia. (21 de enero del 2016). Sentencia C-007/16. M.P. Alejandro Linares Cantillo.

Corte Constitucional de Colombia. (13 de diciembre del 2016). Sentencia C-699/16. M.P. María Victoria Calle Correa.

Corte Constitucional de Colombia. (22 de marzo del 2017). Sentencia C-174/17. M.P. María Victoria Calle Correa. 
Corte Constitucional de Colombia. (17 de mayo del 2017). Sentencia C-332/17. M.P. Antonio José Lizarazo Ocampo).

Cuervo, V., y Márquez, A. (2017, enero-junio). Feminicidio, impunidad o seguridad jurídica en la política criminal colombiana. Revista Verba Iuris, 12(37), 109-118. Recuperado de http://www.unilibre.edu.co/verbaiuris/37/feminicidio-impunidad.pdf

Cultura de Paz. (2010). introducción a los procesos de paz. Quaderns de construcció de Pau. Recuperado de http://escolapau.uab.cat/img/qcp/introduccion_procesos_paz.pdf

Forero, J. (2016, enero-junio). Control de constitucionalidad como garantía jurisdiccional de la función legislativa. Desarrollo normativo, jurisprudencial y doctrinal, desde la perspectiva del derecho constitucional español y colombiano. Revista Republicana, (20), 117-144. Recuperado de http://ojs.urepublicana.edu.co/index.php/revistarepublicana/ article/view/291/265

Groppi. T. (2003). ¿Hacia una justicia constitucional dúctil? Tendencias recientes de las relaciones entre la Corte Constitucional y jueces comunes en la experiencia italiana. Boletín mexicano de derecho comparado, 36(107). Universidad de Siena. Recuperado de http://scielo.unam.mx/scielo.php?pid=S0041-86332003000200002\&script=sci_arttext

Guarín, E., y Aldana, J. (2016, julio-diciembre). Estado jurisdiccional y bien común. Revista Verba Iuris, 11(36), julio-diciembre 2016, pp. 13-26. Recuperado de http://www. unilibre.edu.co/verbaiuris/36/Estado-jurisdiccional.pdf

Hernández, R. (2009). El control de constitucionalidad del procedimiento de reforma constitucional. Santiago de Chile. Recuperado de http://www.redalyc.org/pdf/820/82040120.pdf

López, D. (2016). El derecho de los jueces. Bogotá, Colombia: Editorial Legis S. A.

Llano, J. (2017, enero-junio). Construcción de ciudadanía en la América Latina del siglo XIX: una perspectiva constitucional. Revista Republicana, (22), 209-230. Recuperado de http://ojs.urepublicana.edu.co/index.php/revistarepublicana/article/view/385/340

Luna, A. (2015). La seguridad juridica y las verdades oficiales del derecho. Recuperado de http://site.ebrary.com.sibulgem.unilibre.edu.co:2048/lib/bibliounilibresp/detail. action?docID=11217094

Martínez, A. (2000). Tipos de sentencias en el control constitucional de las leyes: las experiencias colombianas. Estudios socio-jurídicos, (2). ISSN: 0124-0579.

Nogueira, H. (2004). Consideraciones sobre las sentencias de los tribunales Constitucionales y sus efectos en América del Sur. Recuperado de http://www.scielo.cl/scielo.php?script=sci_ar ttext\&pid=S0718-00122004000100005

Olano, H. (2004). Tipología de nuestras, sentencias constitucionales. Recuperado de https:// revistas-colaboracion.juridicas.unam.mx/index.php/vniversitas/article/view/106/84 
Presidencia de la República de Colombia. (24 de noviembre del 2016). Acuerdo final para la terminación del conflicto y la construcción de una paz estable y duradera. Recuperado de http://www.altocomisionadoparalapaz.gov.co/procesos-y-conversaciones/Documentos\%20compartidos/24-11-2016NuevoAcuerdoFinal.pdf

Presidencia de la República de Colombia. (26 de agosto de1 2012). Acuerdo sobre cese al fuego y hostilidades bilateral y definitivo y dejación de armas entre el Gobierno y las Farc-EP. Recuperado de www.altocomisionadoparalapaz.gov.co/mesadeconversaciones/PDF/ cese_y_dejacion_alta-1467636327.pdf

Presidencia de la República de Colombia. (23 de junio del 2016). Acuerdo sobre refrendación. Recuperado de http://www.altocomisionadoparalapaz.gov.co/procesos-y-conversaciones/documentos-y-comunicados-conjuntos/Paginas/Comunicado-Conjunto-Acuerdosobre-Cese-al-fuego-y-de-hostilidades-bilateral-y-Definitivo-y-Dejacion-de-Armas. aspx

Quinche. M. (2014). El control de constitucionalidad. Bogotá, Colombia: Editorial Ibáñez.

Quinche, M. (2015). La acción de inconstitucionalidad. Madrid, España: Universidad del Rosario. Recuperado de http://site.ebrary.com.sibulgem.unilibre.edu.co:2048/lib/ bibliounilibresp/detail.action?docID=11217094

Miranda, M. (2016, enero-junio). La regla o el principio de la selección objetiva en la contratación pública colombiana. Revista Verba Iuris, 11(35), 65-84. Recuperado de http://www.unilibre.edu.co/verbaiuris/35/seleccion-objetiva.pdf

Revelo, F., y Valbuena, J. (2017, julio-diciembre). El decreto 1382 de 2000, por el cual se fijan reglas de reparto en materia de tutela. Un conflicto vigente entre las altas cortes colombianas. Revista IUSTA, 2(47), 59-85. DOI: http://dx.doi.org/10.15332/s19000448.2017.0047.03. Recuperado de http://revistas.usta.edu.co/index.php/iusta/article/ view/3811/3750

Registraduría Nacional del Estado Civil. (2017). Plebiscito 2 de octubre del 2016. Recuperado de http://plebiscito.registraduria.gov.co/99PL/DPLZZZZZZZZZZZZZZZZZ_L1.htm

Rodríguez, J. (2017, enero-junio). Presidencia imperial y desequilibrio de poderes en Colombia. Revista Verba Iuris, 12(37), 79-89. Recuperado de http://www.unilibre.edu.co/ verbaiuris/37/presidencia-imperial.pdf

Turegano, I. (2013). La justicia de transición: concepto, instrumentos y experiencias. Universidad del Rosario. Recuperado de http://site.ebrary.com.sibulgem.unilibre.edu.co:2048/lib/ bibliounilibresp/reader.action?docID $=11312685$ 